\title{
KAPTUR: exploring the nature of visual arts research data and its effective management
}

\author{
Leigh Garrett \\ University for the Creative Arts \\ Visual Arts Data Service \\ Falkner Road \\ Farnham \\ GU9 7DS \\ lgarrett@ucreative.ac.uk
}

\author{
Marie-Therese Gramstadt \\ University for the Creative Arts \\ Visual Arts Data Service \\ Falkner Road \\ Farnham \\ GU9 7DS \\ mgramstadt@ucreative.ac.uk
}

\begin{abstract}
KAPTUR (2011-2013), funded by JISC and led by the Visual Arts Data Service (VADS), is a highly collaborative project involving four institutional partners: the Glasgow School of Arts; Goldsmiths, University of London; University for the Creative Arts; and the University of the Arts London. The preservation and publication of research data is seen as positive and all UK Research Councils now require it as a condition of funding (RCUK 2012). As a result a network of data repositories are emerging (DataCite 2012a), some funded by Research Councils, others by institutions themselves. However, research data management practice within the visual arts appears ad hoc. None of the specialist arts institutions within the UK has implemented research data management policies (DCC 2011a), nor established research data management systems. KAPTUR seeks to investigate the nature of visual arts research data, making recommendations for its effective management; develop a model of best practice applicable to both specialist arts institutions and arts departments in multidisciplinary institutions; and apply, test and refine the model with the four institutional partners. This paper will explore the nature of visual arts research data and how effective data management can ensure its long term usage, curation and preservation.
\end{abstract}

Digital Curation. Publication. Research Data. Research Management. Pilot. Visual Arts.

\section{INTRODUCTION}

The overarching objective of KAPTUR (2011-13) is to discover, develop and disseminate a sectoral model of best practice in the effective management of research data in the visual arts across the UK higher education sector.

This highly collaborative project, led by the Visual Arts Data Service, a Research Centre of the University for the Creative Arts, draws and builds upon the knowledge, experience and practice of four institutional partners, including: Glasgow School of Art (GSA); Goldsmiths, University of London; University for the Creative Arts (UCA); and University of the Arts London (UAL); and funded by the JISC Managing Research Data programme (2011-13).

\section{RESEARCH DATA MANAGEMENT IN THE UK}

Research Councils, research teams and researchers themselves are under considerable pressure to make publicly funded research data freely available. As a result, the publication of research data is increasingly a requirement of funding, for example the Arts and Humanities Research Council (AHRC 2012). Equally important is data transparency and the facility for researchers to access existing datasets to test the validity and reliability of the data and underlying research methods; to reinterpret the data; and to preserve the data for future re-use. Several universities, for example the University of Edinburgh, have established institutional research data management systems to support the deposit and preservation of research data (University of Edinburgh 2012a), whilst others are in the process of piloting services and establishing policies and procedures which actively support researchers to manage their data effectively, such as Northumbria University (2012). In addition, many of the research councils have established repositories themselves, for example, the UK Data Archive at the University of Essex, which curates research data in the social sciences and humanities (UK 
Data Archive 2012a), and the Natural Environment Research Council, which supports a network of data centres across its disciplinary areas (NERC 2012).

\subsection{Digital Curation Centre (DCC)}

In recognition of the growing importance of research data, the Digital Curation Centre (DCC) was established in 2004.to embed effective management of research data management practices across the higher education sector. Funded by JISC the DCC has evolved and now provides an excellent range of services including: resources, training and tools and a UK-wide programme of events and community fora on research data curation. These activities support the management of research data throughout its whole lifecycle from creation to storage and disposal; the DCC Curation Lifecycle Model provides more detail (DCC 2011b).

\subsection{JISC Managing Research Data Programme (2009-11)}

The significant level of funding provided through the JISC Managing Research Data programme (2009-11) and the breadth of projects highlights the significance of effective Research Data Management (RDM) to UK Higher Education.

This first round of the programme resulted in a wide range of re-usable technical systems, policies, and training materials. Of particular relevance for the KAPTUR project were: the Incremental (2009-11) project's scoping study (Incremental 2010) and online training materials (University of Cambridge 2011, University of Glasgow 2011); the DataFlow system originally developed through the ADMIRAL (2009-11) project (University of Oxford 2012); training materials developed by Research Data MANTRA (2009-11) project (University of Edinburgh 2012b); and the Project CAiRO (Curating Artistic Research Output) (2009-11) postgraduate teaching module for the creative and performing arts (Project CAiRO 2011).

\subsection{Research Councils UK}

Research Councils UK (RCUK) are responsible for funding around $£ 3$ billion of research across the higher education sector. In their Common Principles on Data Policy (RCUK 2011) they state:

Making research data available to users is a core part of the Research Councils' remit [...]

This has been further emphasised with the publication of a draft policy on access to research outputs which has significant implications for the management of research data as soon as summer 2012 (RCUK 2012).

In May 2011 the Engineering and Physical Sciences Research Council (EPSRC) published a Policy Framework on Research Data (EPSRC 2011); this includes the expectation that all institutions in receipt of funding will have developed a roadmap by May 2012, with the aim of meeting the EPSRC expectations by May 2015. While the focus of the KAPTUR project is on the visual arts, three out of the four institutional partners are also in receipt of funding from the EPSRC, reflecting an increasing trend towards cross-disciplinary collaboration (KAPTUR blog 2012).

The requirement for effective management of research data extends across a range of funders in the UK and beyond. Six members of RCUK, including the Arts and Humanities Research Council (AHRC) request a Data Management Plan (DMP) at the application stage, as do other funders, such as the Wellcome Trust.

\section{PRACTICE IN THE VISUAL ARTS}

Despite these motivators, none of the specialist arts institutions within the UK has yet implemented research data management policies or systems.

In the absence of policies or the appropriate infrastructure to support the storage, presentation and preservation of research data, the management of this data is currently left to the individual visual arts researcher.

Little work has been undertaken to understand the distinctive and varied nature of research data in the visual arts, and even less to understand how this data can be curated, preserved, used, and its potential impact assessed.

\section{KAPTUR LEADS THE WAY}

KAPTUR seeks to promote, support and embed effective research data management practices within the visual arts. The project's objectives are:

(a) To investigate the current state of the management of research data in the visual arts.

(b) To develop a model of best practice applicable to both specialist arts institutions and arts departments in multidisciplinary institutions.

(c) To apply, test and embed the model with the four institutional partners.

(d) To create a pilot demonstrator research data management system. 
These objectives will be addressed through the following five work packages: environmental assessment; modelling; technical infrastructure; training; and sustainability.

\section{UNDERSTANDING THE NATURE OF RESEARCH DATA IN THE VISUAL ARTS}

By its very nature, research in the arts is highly complex and varied, often comprising a wide variety of outputs and formats which present researchers, repository managers and technology teams with many discipline specific issues. The methods and processes which generate this research are just as varied and complex. Research endeavour in the arts relies heavily on sketchbooks, logbooks, journals, and workbooks. Alongside this data, a wide range of related project documentation and protocols are also created. The often physical nature of research data in the arts, its security and preservation, presents researchers and curators with significant problems and greatly increases the risk of data loss and deterioration. While technology offers considerable potential to the arts to support the safe storage and preservation of research outputs and related data and to enhance access, the highly distinctive nature of the arts and its research methods also presents enormous technical challenges with regard to formats, standards, roles and responsibilities, and policies.

\subsection{Method}

The KAPTUR Environmental Assessment report (Garrett et al. 2012) includes the findings of a literature review and 16 one-hour recorded interviews with visual arts researchers. This qualitative data was analysed collaboratively within the project team in order to answer two research questions:

- What is the nature of visual arts research data?

- How can we support the needs of visual arts researchers through institutional infrastructure?

For the purposes of the report the definition of visual arts encompassed the following subject areas: Applied Arts, Architecture, Design, Fine Art, History and Theory of Art, Media, Museum Studies and Conservation, and Professional Practice. This was then expressed within four broad categories of visual arts researcher:

- Artist-researcher I (more analogue practice)

- Artist-researcher II (more digital practice)

- Designer-researcher

- Art or cultural historian
Each Project Officer interviewed four visual arts researchers from these categories to enable comparisons to be made across the four institutions and between disciplinary areas.

The aim of the interviews was to understand the current state of RDM in the visual arts to inform subsequent KAPTUR work packages and ensure their relevance to the needs of visual arts researchers. Additionally the report provides a snapshot which can be used to measure the project's progress and future impact.

\subsection{Findings}

Research data can be described as data which arises out of, and evidences, research. This can be classified as observational, including: sensor data; experimental; simulation; derived or compiled data for example databases and 3D models; or reference or canonical for example, a collection of smaller datasets gathered together (University of Edinburgh 2011a). Examples of visual arts research data may include sketchbooks, log books, sets of images, video recordings, trials, prototypes, ceramic glaze recipes, found objects, and correspondence.

The project team found that the nature of visual arts research data can be both: tangible and intangible; digital and physical; heterogeneous and infinite; and complex and complicated (Garrett et al. 2012).

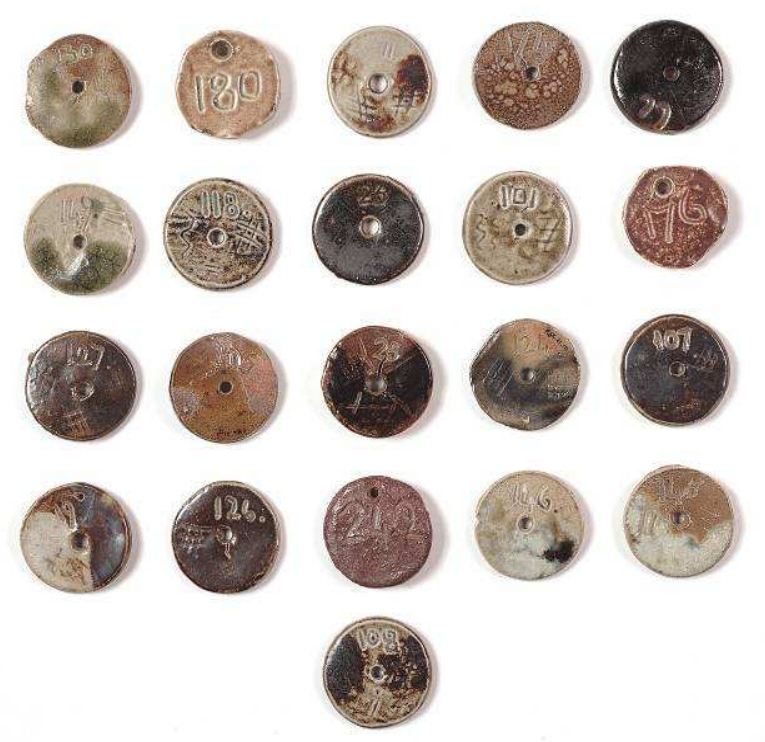

Figure 1: Denise Wren, 21 small tiles used to demonstrate different saltglaze tests on stoneware, 1960s. (C) Rosemary Wren/Crafts Study Centre 2004.

Photo: David Westwood. Available from www.vads.ac.uk

\subsubsection{Tangible and intangible}


Research data can be perceived by touch in the form of physical objects. For example a sketchbook could be considered tangible research data; however the tacit knowledge which informed its creation may remain intangible. Tacit knowledge is particularly relevant to artistic practice and practiceled teaching, as one of the interviewee's described:

"artistic practice as research"] probably involves a lot more gut instinct and intuition than would be permissible in a scientific experiment

Depending on the research methodology, tacit knowledge may become explicit as part of the research output or it may need to be recorded through the research data for example, through annotations, blog posts, or correspondence.

\subsubsection{Heterogeneous and infinite}

Although other subject disciplines such as Engineering have reported a wide variety of research data types and file formats (Howard et al. 2010), with visual arts data this is even more heterogeneous due to the nature of artistic research. Artistic research is relatively new compared to other disciplines, arising from the introduction of art and design research degrees in the 1990s. As a result, research methodologies may be borrowed or adapted from other disciplines, such as Social Science, and new and innovative research methods may also be employed. Gray and Delday (2010) describe the process of artistic research as follows:

It is never a smooth and homogenous process but fluid, 'wet' and folded, if not at times messy, fuzzy and tumultuous.

(cited in Mey 2010)

The nature of visual arts research data is potentially infinite, never ending. This is particularly the case with artistic research that is based on "the self", as Gemmell and Giddens describe:

We are always in a state of becoming, always unfinished.

(cited in Griffiths 2010)

One of the interviewees described their research process as much more of a continuum, without necessarily distinct or distinguished stages, but with "organisational moments"; at these points research data might be actualised as a natural part of the research process such as writing or "trials in the studio".

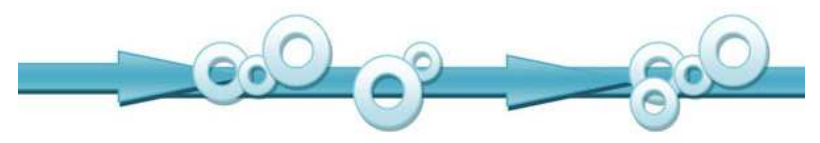

Figure 2: visual arts research as a continuum over time with "organisational moments" at which research data may be actualised (Garrett et al. 2012)

Other "organisational moments" might include: compiling materials for an exhibition; externally imposed information required for the institution or funders; making a grant application, writing a paper; institutional duties such as lectures, tutorials, or other learning and teaching events; or filing information.

KAPTUR will build upon the notion of "organisation moments" to create a model for visual arts research data in order to suggest possible intervention points when support and advocacy work would be most effective.

\subsubsection{Complex and complicated}

Visual arts research data presents many challenges for the data curator, for example in terms of classifying materials and enabling access. An interviewee commented:

[my practice is] complex and complicated. [For my PhD] I thought I was doing sculpture, I ended up doing book design and photography and now I'm involved in performance practice more than anything else $[\ldots]$

Some of the issues are discussed in a case study produced for the JISC-funded Kultivate (2010-11) project; Gray (2011) describes a workflow tested in conjunction with the researcher which was "designed to support the archiving of live artwork" (Gray 2011). This resulted in the creation of a "granular catalogue record (or 'score')" which included:

videos of the performance, video interviews with the artist, scans of related promotional material, [and] digital photographs of objects involved (Gray 2011)

By involving the artist-researcher from the beginning of the process it was possible to establish "the focus of the documentation process" (Gray 2011).

\subsubsection{Digital and physical}

Visual arts research data can take the form of digital files or physical objects. One of the nine EPSRC Expectations (2011) mentions physical research data:

Publicly-funded research data that is not generated in digital format will be stored in a manner to facilitate it being shared in the event of a valid request for access to the data being received $[\ldots]$ 


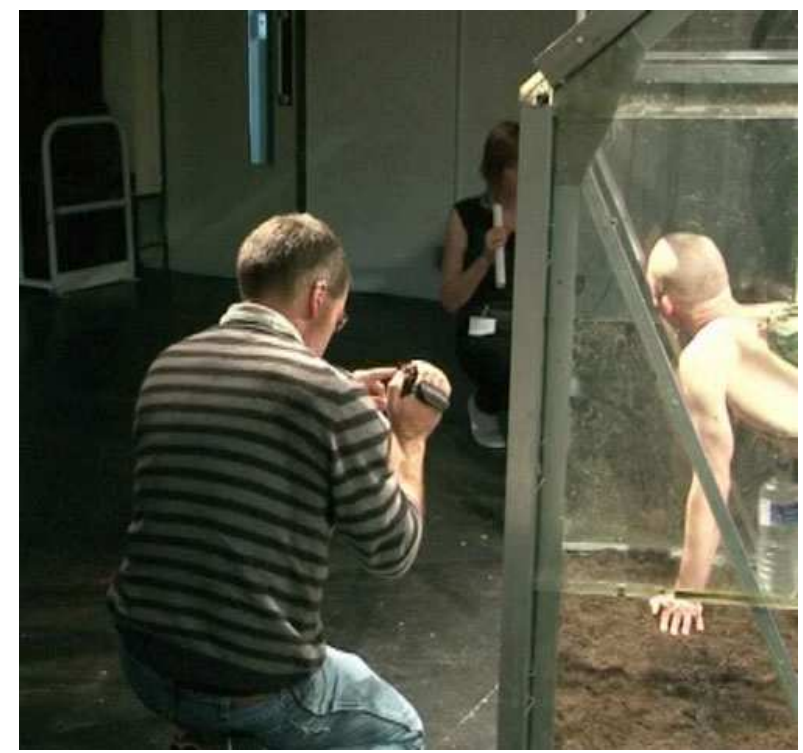

Figure 3: Paul Hurley's 'Becoming Snail'. (C) University of Bristol 2009.

The implication is either that a programme of digitisation is required for future research data, or that at least metadata records will be required for physical research data which include access information.

A useful point to consider is that the research data of today may well be the special collections of the future (cited in Murtagh 2011). Taking the example of the Stanley Kubrick Archive which is housed in the University Archives and Special Collections Centre, University of the Arts London:

[...] a staggering collection of some 800 large boxes containing scripts, stills, props, posters, costumes, documents, equipment and a vast library of books [...]

(Kemp 2006)

This invites comparison with the response of an interviewee:

[...] I'm just like anyone else l've got boxes of stuff, l've got a garden shed and then I've got files, l've got electronic files and I've got physical files, l've got ring binders full of clippings, full of photographs, and l've got documents of exhibitions that l've been in, l've got catalogues of exhibitions l've been to $[\ldots]$

The description of "stuff" highlights the need for appraisal and selection (Harvey 2007) as part of the data management lifecycle for both digital and physical items.

\section{FACILITATING SECTOR WIDE CHANGE}

The Environmental Assessment report findings suggest that there is an overall lack of awareness

Figure 4: Colour exercise: Exploration of secondary central hues, 1960. Basic Design Collection. (O National Arts Education Archive Non-commercial. Available from www.vads.ac.uk

of research data, partly due to the terminology itself, and partly due to situated, rather than normative, archiving and documentation practices (Garrett et al. 2012). KAPTUR seeks cultural change that would empower visual arts researchers to make informed decisions about their research data. One approach is to highlight the benefits of effective research data management for key stakeholders.

Some of the benefits of well managed research data for researchers are: increased impact through

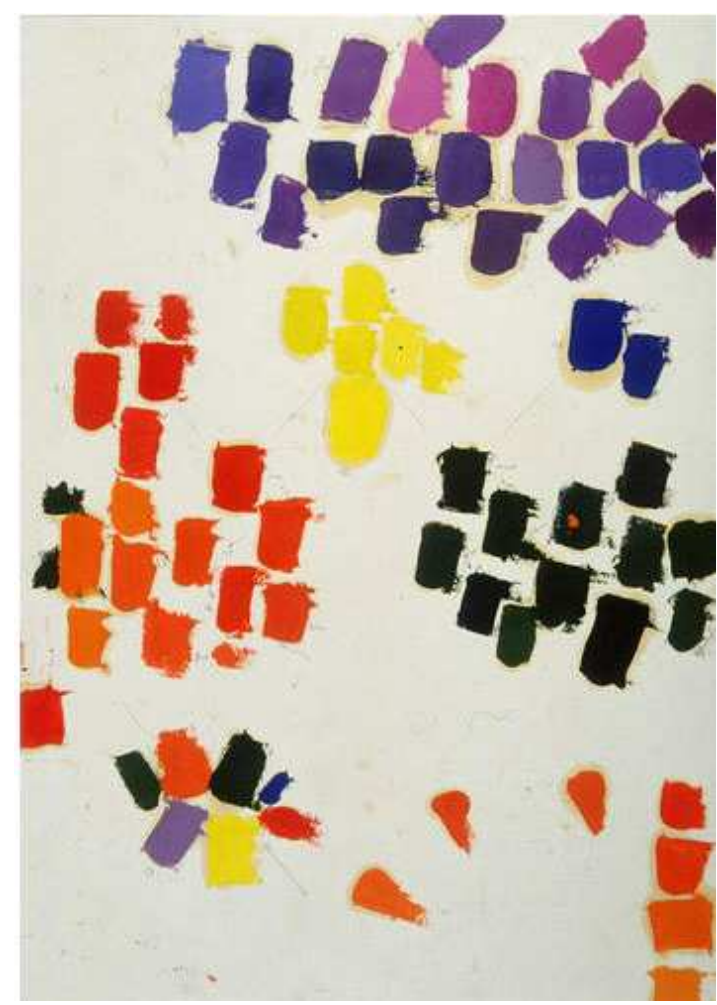

making research data accessible such as increased citations (DataCite 2012b); time saved during the preparation of research outputs, or when handling institutional, funder and Freedom of Information (FOI) requests, as the information is more readily available; a reliable record of evidence for the research undertaken; and an increase in resources for researchers themselves to access and re-use (UK Data Archive 2012b). The Visual Arts Data Service (VADS) is an example of a data repository (DataCite 2012a) that makes visual arts research data available online.

For institutions, the effective management of research data can ensure that FOI requests are responded to in a timely manner; provide evidence 
of valid research to protect the institution's reputation; mitigate the potential loss of research data (UK Data Archive 2012b); and enhance successful funding applications by demonstrating institutional best practice and support in this area, for example the JISC-funded HALOGEN project (2010) and The Impact of Diasporas research programme (2011-15) funded by the Leverhulme Trust (University of Leicester 2012).

\subsection{Institutional Policies}

The project team embarked on the modelling work package in February 2012. Following the initial meeting of the Project Steering Group, at which the findings of the Environmental Assessment report were presented for discussion, the Group recommended the formation of institutional working groups to consider policy formation and implementation plans. All four partner institutions are expected to have research data management policies by the end of the project (March 2013).

\subsubsection{Method}

Discussion during the KAPTUR Steering Group meeting (February 2012) informed the method; and the project team also benefitted from attending a two-day workshop on policies through the JISC Managing Research Data programme, hosted by the University of Leeds (March 2012).

Each partner appointed a Project Officer to coordinate KAPTUR at an institutional level, as well as a Project Sponsor to champion the project at senior management level. The first step was to establish working groups at each institution. Building upon the relationships established through the environmental assessment, these groups will include a wide range of stakeholders: IT, Research Office, Researchers, Library staff, FOI staff, and Senior Management, with the intention of creating a research management policy for their respective institutions.

The project team has developed a discussion paper to inform institutional committees and guide the working groups. The paper makes reference to the work already undertaken by the University of Edinburgh (2011b) in the formation of their research data management policy. After the paper has been discussed within individual institutions, draft institutional policies will be drawn up $b$ the working groups with the aim of seeking high-level approval in the autumn 2012; once approved they will be made available online by means of the Digital Curation Centre's website (DCC 2011a).

\subsubsection{Findings}

Some preliminary findings are expected by summer 2012. The intention is that the RDM policies will confirm senior management support for research data and help to embed good practice from a topdown approach, complementing the bottom-up perspective of the visual arts researchers.

The process of building a policy is seen as a highly iterative process. Once the policy has been approved, it should remain a living document in order to support changes and amendments as practice, knowledge, environments, institutions and related policies evolve, an example of this is the University of Melbourne's RDM policy (2010).

\subsection{Technical Infrastructure}

One of the core elements of the project is to develop a pilot research data management system. This will be tested and reviewed by the partners with the intention of institutional adoption.

\subsubsection{Method}

The technical work package commenced in January 2012 with two primary objectives: to investigate the key user requirements of a research data management system in the visual arts; and to specify and procure an appropriate system.

The following were identified as key stakeholders: researchers; infrastructure service providers; funders; institutions; the research community; students; academic staff; professional support staff; and the wider community.

Building upon the work already undertaken during the creation of the Environmental Assessment report, the project team focused on collecting data from the KAPTUR Project Officers and IT service providers at each of the partner institutions.

Data was collected by means of analysis of the Environmental Assessment findings, and through interviews with each of the partner Project Officers and IT Management, Infrastructure and Support staff.

\subsubsection{Findings}

Requirements were identified in four key areas: storage, interface; system and institutional.

Storage requirements reflect the diverse nature of the data to be stored by the system and include: metadata; an extensive range of multimedia and text-based file types; and a range of other data types including archival files, transcription, external links and application files.

Interface requirements: the system will need to ensure that data is stored and managed effectively. The system will need to have a workflow which ensures appropriate authentication, data upload, quality assurance, publication, preservation and data disposal. A search function was also 
identified as an essential requirement to ensure the discovery and appropriate re-use of data. Finally, the interface would have to comply with appropriate web and legal standards regarding usability.

System requirements: the investigation considered the current operating environments of the partner institutions. The following were considered as requirements: a system which could be hosted on a Microsoft Windows operating system, although this could be a Virtual Server with a Unix system hosted on a Windows server; storage that could potentially be unlimited and consideration of cloud storage solutions; enable files of up to $1 \mathrm{~Gb}$ to be uploaded; compatibility with existing infrastructure (including authentication, research repository, backup and disaster recovery services); finally the system would need to be robust, web based and secure.

Institutional requirements: the system would need to be capable of adapting to institutional workflows; provide statistical reporting tools; comply with UK and EU legislation on data management and storage; and provide for the preservation and disposal of research data as required.

The user requirement is currently being considered by the partners and once approved will provide the basis for the tender specification, which will be issued to potential software suppliers in April 2012.

\subsection{Building Capacity}

The KAPTUR project is ongoing and two further areas are still to be considered, these include: training and support, and sustainability.

\subsubsection{Training and support}

Dissemination is an ongoing and fundamental element of the project. The project team will be working closely with the wider arts community, primarily through the KULTUR II group of arts institutions and departments; the Repositories Support Project (RSP); and the DCC to develop workshops, practice guides, toolkits, and training materials to learn and benefit from the enhanced tools and services, and from best practice, policies and procedures emerging across the sector.

The team will also be working widely to disseminate project developments, outcomes and lessons learned through UK conferences, workshop reports, and journal publications. In addition, they will publish emerging knowledge of good practice, including all policies, plans, specifications, guidelines, toolkits and training materials across the broader higher education community by showcasing a successful model for the curation and management of arts research data management online via partner institutional repositories and the project website and blog.
In addition, the four partners will each write a case study documenting the creation, implementation and embedding of research management data policies and infrastructure within their own institution, to be published online and presented at the end of project conference in March 2013.

\subsubsection{Sustainability}

As part of the business and financial work package, the project team will investigate sustainability models and critical success factors which impact on the successful implementation and embedding of research data management policies and infrastructure in the arts, by comparing and contrasting approaches and structures within the diverse range of partner institutions; this data will be collated, analysed and presented in the form of business and sustainability plans for each institution.

\section{CONCLUSION}

The KAPTUR project is approximately a third of the way through its journey. The project team have completed the Environmental Assessment report and now have a much better appreciation of the needs of visual arts researchers' data management needs; work is well underway is specifying a research data management system which will address the particular needs of researchers and institutions in the visual arts; and all four institutional partners have established working groups, led by senior management, to consider, develop and embed research data management policies.

In the longer term, the project is expected to have a significant and positive impact on the availability, discoverability and re-use of research data in the visual arts. This will enhance collaborative working relationships; extend knowledge across the visual arts community to support and enhance learning, teaching and research; promote greater awareness about visual arts research and methods; and enable the visual arts sector to respond and successfully extend its research and funding potential.

\section{ACKNOWLEDGEMENTS}

KAPTUR would like to thank the JISC for funding this project, and in particular Simon Hodson, JISCMRD Programme Manager. Thanks are also due to the researchers who freely gave of their time to take part in the interviews for the Environmental Assessment report.

\section{REFERENCES}


AHRC. (2012) Research Funding Guide. http://www.ahrc.ac.uk/FundingOpportunities/Docum ents/Research\%20Funding\%20Guide.pdf (retrieved 5 April 2012).

DataCite. (2012a) Repositories.

http://datacite.org/repolist (retrieved 4 April 2012).

DataCite. (2012b) Why cite data?

http://datacite.org/whycitedata (retrieved 4 April 2012).

DCC. (2011a) UK Institutional data policies. http://www.dcc.ac.uk/resources/policy-andlegal/institutional-data-policies (retrieved 4 April 2012).

DCC. (2011b) DCC Curation Lifecycle Model. http://www.dcc.ac.uk/resources/curation-lifecyclemodel (retrieved 4 April 2012).

EPSRC. (2011) EPSRC Policy Framework on Research Data. http://www.epsrc.ac.uk/about/standards/researchda ta/Pages/default.aspx (retrieved 3 April 2012).

Garrett, L., Gramstadt, M-T, Burgess, R., Murtagh, J., Spalding, A. and Nadim, T. (2012) JISC funded KAPTUR project environmental assessment report. Visual Arts Data Service (VADS), a Research Centre of the University for the Creative Arts. http://www.research.ucreative.ac.uk/1054/ (retrieved 3 April 2012).

Gray, S., 2011. Documenting Performance Art for the

Archive.

http://www.vads.ac.uk/kultur2group/casestudies/Bri stol2011.pdf (retrieved 4 April 2012).

Griffiths, M. (2010) Research and the Self. In: Biggs, M. and Karlsson, $H$. eds. The Routledge Companion to Research in the Arts. Abingdon: Routledge, 167-185.

Harvey, R. (2007) Appraisal and Selection. In: Curation Reference Manual. Digital Curation Centre. http://www.dcc.ac.uk/resources/curationreference-manual (retrieved 4 April 2012).

Howard, T., Darlington, M., Ball, A., Culley, S. and McMahon, C. (2010) Understanding and Characterizing Engineering Research

Data for its Better Management. University of Bath. http://opus.bath.ac.uk/20896/1/erim2rep100420mjd 10.pdf (retrieved 3 April 2012).

Incremental. (2010) Scoping study and implementation plan: A pilot project for supporting research data management. http://www.lib.cam.ac.uk/preservation/incremental/d ocuments/Incremental_Scoping_Report_170910.p df (retrieved 3 April 2012).

KAPTUR blog. (2012) Funders and trends in artistic research

grants. http://kaptur.wordpress.com/2012/03/09/funderstrends-artistic-research/ (retrieved 3 April 2012).

Kemp, P. (2006) The Kubrick Legacy. In: Alumni Magazine, University of the Arts London, Issue 5 Spring/Summer 2006, pp. 8-17.

KULTUR II Group. http://www.vads.ac.uk/kultur2group (retrieved 8 April 2012).

Mey, K. (2010) Creativity, Imagination, Values why we need artistic research. In: Textures, the 6th European meeting of the Society for Literature, Science and the Arts, Riga, Latvia, 15-19 June 2010. (Unpublished)

Murtagh, J. (2011) An arts perspective: day two and three - the sixth DCC Roadshow on data management. http://www.dcc.ac.uk/news/artsperspective-dcc-roadshow (retrieved 4 April 2012).

NERC. (2012) Data centres. http://www.nerc.ac.uk/research/sites/data/ (retrieved 5 April 2012).

Northumbria University. (2012) DATUM: Research data management. http://www.northumbria.ac.uk/sd/academic/ceis/re/i $\mathrm{src} /$ themes/rmarea/datum/ (retrieved 5 April 2012).

Project CAiRO. (2011) Managing Creative Arts Research Data (MCARD) training module. http://www.projectcairo.org/node/9 (retrieved 5 April 2012).

RCUK. (2012) RCUK Proposed Policy on Access to Research Outputs. http://www.openscholarship.org/upload/docs/applic ation/pdf/2012-

03/rcuk_proposed_policy_on_access_to_research _outputs.pdf (retrieved 3 A pril 2012).

RCUK. (2011) RCUK Common Principles on Data Policy.

http://www.rcuk.ac.uk/research/Pages/DataPolicy.a spx (retrieved 3 April 2012).

UK Data Archive. (2012a) About Us: About the Archive. http://www.dataarchive.ac.uk/about/archive (retrieved 5 April 2012).

UK Data Archive. (2012b) Why share data? http://www.data-archive.ac.uk/createmanage/planning-for-sharing/why-share-data (retrieved 5 April 2012).

University of Cambridge. (2011) Support for Managing Research Data. http://www.lib.cam.ac.uk/dataman/ (retrieved 5 April 2012).

University of Edinburgh. (2012a) Edinburgh DataShare. http://datashare.is.ed.ac.uk/ (retrieved 5 April 2012). 
University of Edinburgh. (2012b) MANTRA

Research Data Management Training. http://datalib.edina.ac.uk/mantra/ (retrieved 5 April 2012).

University of Edinburgh. (2011a) Defining research data. http://www.ed.ac.uk/schools-

departments/information-

services/services/research-support/data-

library/research-data-mgmt/data-mgmt/researchdata-definition (retrieved 3 April 2012).

University of Edinburgh. (2011b) Research Data Management Policy. http://www.ed.ac.uk/schoolsdepartments/information-services/about/policiesand-regulations/research-data-policy (retrieved 5 April 2012).

University of Glasgow. (2011) Data management support http://www.gla.ac.uk/services/datamanagement/ (retrieved 5 April 2012).

University of Leicester. (2012) The Impact of Diasporas on the Making of Britain: evidence, memories, inventions. http://www2.le.ac.uk/projects/impact-of-diasporas (retrieved 5 April 2012).

University of Melbourne. (2010) Review of Policy on the Management of Research Data and Records.

http://research.unimelb.edu.au/integrity/conduct/dat a/review (retrieved 5 April 2012).

University of Oxford. (2012) DataFlow. http://www.dataflow.ox.ac.uk/ (retrieved 5 April 2012). 